\title{
GABAergic Depolarization of the Axon Initial Segment in Cortical Principal Neurons Is Caused by the $\mathrm{Na}-\mathrm{K}-2 \mathrm{Cl}$ Cotransporter NKCC1
}

\author{
Stanislav Khirug, ${ }^{1 *}$ Junko Yamada, ${ }^{1 *}$ Ramil Afzalov, ${ }^{1}$ Juha Voipio, ${ }^{1}$ Leonard Khiroug, ${ }^{2}$ and Kai Kaila ${ }^{1,2}$ \\ ${ }^{1}$ Department of Biological and Environmental Sciences and ${ }^{2}$ Neuroscience Center, University of Helsinki, FIN-00014 Helsinki, Finland
}

\begin{abstract}
GABAergic terminals of axo-axonic cells (AACs) are exclusively located on the axon initial segment (AIS) of cortical principal neurons, and they are generally thought to exert a powerful inhibitory action. However, recent work (Szabadics et al., 2006) indicates that this input from AACs can be depolarizing and even excitatory. Here, we used local photolysis of caged GABA to measure reversal potentials $\left(E_{\mathrm{GABA}}\right)$ of $\mathrm{GABA}_{\mathrm{A}}$ receptor-mediated currents and to estimate the local chloride concentration in the AIS compared with other cellular compartments in dentate granule cells and neocortical pyramidal neurons. We found a robust axo-somato-dendritic gradient in which the $E_{\mathrm{GABA}}$ values from the AIS to the soma and dendrites become progressively more negative. Data from $\mathrm{NKCC1}^{-/-}$and bumetanide-exposed neurons indicated that the depolarizing $E_{\mathrm{GABA}}$ at the AIS is set by chloride uptake mediated by the $\mathrm{Na}-\mathrm{K}-2 \mathrm{Cl}$ cotransporter NKCC1. Our findings demonstrate that spatially distinct interneuronal inputs can induce postsynaptic voltage responses with different amplitudes and polarities as governed by the subcellular distributions of plasmalemmal chloride transporters.
\end{abstract}

Key words: axon initial segment; NKCC1; KCC2; synapse; chloride; caged GABA

\section{Introduction}

The axon initial segment (AIS) of cortical principal neurons is selectively innervated by a subclass of interneurons, the chandelier or axo-axonic cells (AACs) (Freund and Buzsaki, 1996; Somogyi et al., 1998). This strategic location of GABAergic synapses on the AIS has generally been thought to endow the AACs with a powerful inhibitory action on the output of principal neurons. However, recent work on neocortical layer $2 / 3$ pyramidal neurons in rats and humans has shown that AACs can evoke depolarizing and even excitatory instead of inhibitory responses, because the reversal potential of $\mathrm{GABA}_{\mathrm{A}}$ receptor-mediated currents $\left(E_{\mathrm{GABA}}\right)$ in the AIS is at a much more depolarized level (by $\sim 20 \mathrm{mV}$ ) than the resting membrane potential (Szabadics et al., 2006). In contrast, somatic and dendritic $\mathrm{GABA}_{\mathrm{A}}$ receptormediated responses evoked by basket cells in these neurons are hyperpolarizing. This compartmentalized $E_{\mathrm{GABA}}$ indicates a steady-state intracellular gradient of $\mathrm{Cl}^{-}$that was attributed to a differential subcellular distribution of the chloride-extruding

Received Aug. 28, 2007; revised March 27, 2008; accepted March 27, 2008.

This work was supported by the Academy of Finland, the Sigrid Juselius Foundation, and the Finnish Cultural Foundation. K.K. is a member of the Nordic Center of Excellence for Water Imbalance-Related Disorders and of the Finnish Center of Excellence in Molecular and Integrative Neuroscience Research. We thank Dr. Mark Farrant for discussions and comments on an early version of this manuscript and Dr. Peter Blaesse for providing expertise on electroporation experiments and helpful discussions. We are grateful to Dr. Beverly H. Koller (University of North Carolina, Chapel Hill, NC) and to Dr. Pico Caroni (Friedrich Miescher Institut, Basel, Switzerland) for providing the transgenic mice used in this study.

*S.K. and J.Y. contributed equally to this work.

Correspondence should be addressed to Kai Kaila, Department of Biological and Environmental Sciences, University of Helsinki, P.0. Box 65, FIN-00014 Helsinki, Finland. E-mail: kai.kaila@helsinki.fi.

DOI:10.1523/JNEUROSCI.0908-08.2008

Copyright $\odot 2008$ Society for Neuroscience $\quad$ 0270-6474/08/284635-05\$15.00/0
$\mathrm{K}-\mathrm{Cl}$ cotransporter, $\mathrm{KCC} 2$, with a high level of $\mathrm{KCC} 2$ in the somata and dendrites and a very low level in the AIS (Szabadics et al., 2006).

The central role of KCC2 in the generation of a transmembrane chloride gradient that results in hyperpolarizing GABAergic responses in cortical neurons is well established (Rivera et al., 1999; Payne et al., 2003). However, the mere absence of KCC2 cannot account for the strikingly positive $E_{\mathrm{GABA}}$ values at the AIS, because in the complete absence of $\mathrm{Cl}^{-}$transport, $E_{\mathrm{GABA}}$ would achieve a level close to and only slightly more depolarized than the resting membrane potential (Kaila et al., 1993; Farrant and Kaila, 2007). Thus, the depolarizing $\mathrm{GABA}_{\mathrm{A}}$ receptor-mediated response at the AIS requires the presence of a $\mathrm{Cl}^{-}$uptake mechanism. The present work focuses on the identification of this mechanism and on its role in the subcellular compartmentalization of $E_{\mathrm{GABA}}$.

\section{Materials and Methods}

Experimental animals. The experiments were approved by the Animal Care and Use Committee, University of Helsinki. The animals used in this study included a mouse line with disruption of the Slc12a2 gene that codes for the $\mathrm{Na}-\mathrm{K}-2 \mathrm{Cl}$ isoform NKCC1 (Pace et al., 2000), as well as a transgenic line expressing membrane-targeted enhanced green fluorescent protein (EGFP) in a small subset of dentate gyrus cells (DGCs) under the Thyl promoter (Thy1-mGFP', L21) (De Paola et al., 2003; Galimberti et al., 2006). These mice were generously provided by Dr. Beverly H. Koller (Department of Genetics, University of North Carolina, Chapel Hill, NC) and Dr. Pico Caroni (Friedrich Miescher Institut, Basel, Switzerland), respectively. In experiments on NKCC1 functionality, we used hippocampal slices from homozygous $\mathrm{NKCC1}^{-/-}$animals and their wild-type (WT) $\left(\mathrm{NKCC1}^{+/+}\right)$littermates. Heterozygous Thy1$m G F P^{s} \mathrm{~L} 21$ mice were used for subcellular real-time imaging of DGCs in 
gramicidin patch-clamp recordings (see below). Some experiments were performed on slices from Wistar rats.

Preparation and maintenance of slices. Hippocampal slices and neocortical slices from postnatal day 16-20 mice and rats were used in the present study. The animals were anesthetized with pentobarbital, and $350 \mu \mathrm{m}$ transverse brain slices were cut using a VT 1000S vibratome (Leica, Wetzlar, Germany). Slices were bathed in the standard physiological solution containing the following (in $\mathrm{mM}$ ): $124 \mathrm{NaCl}, 3 \mathrm{KCl}, 2 \mathrm{CaCl}_{2}$, $25 \mathrm{NaHCO}_{3}, 1.1 \mathrm{NaH}_{2} \mathrm{PO}_{4}, 2 \mathrm{MgSO}_{4}$, and $10 \mathrm{D}$-glucose (equilibrated with $95 \% \mathrm{O}_{2}$ and $5 \% \mathrm{CO}_{2}, \mathrm{pH} 7.4$, at the experimental temperature of $\left.32^{\circ} \mathrm{C}\right)$. Tetrodotoxin ( $1 \mu \mathrm{M}$; Sigma, St. Louis, MO) and CGP55845A [(2S)-3-[(15)-1-(3,4-dichlorophenyl)ethyl] amino-2-hydroxypropyl)(phenylmethyl)phosphinic acid] ( $3 \mu \mathrm{m}$; Sigma) were added to block $\mathrm{Na}^{+}$-dependent action potentials and $\mathrm{GABA}_{\mathrm{B}}$ receptors. The slices were allowed to recover at $36^{\circ} \mathrm{C}$ for $1 \mathrm{~h}$ before the experiments were started. Slices were positioned in a submerged-type recording chamber (volume, $\sim 1 \mathrm{ml}$ ). During the experiments, the chamber was continuously perfused at a rate of $1 \mathrm{ml} / \mathrm{min}$. Bumetanide and bicuculline (Sigma) were applied at a concentration of $10 \mu \mathrm{M}$ (Sipilä et al., 2006). The data on bumetanide are from slices that were exposed to the drug throughout the experiment.

Electrophysiology. Gramicidin perforated patch-clamp recordings were done using an EPC 10 amplifier (HEKA Elektronik, Lambrecht/ Pfalz, Germany). The patch pipette solution contained $150 \mathrm{~mm} \mathrm{KCl,} 10$ mM HEPES (pH adjusted to 7.2 with $\mathrm{KOH}$ ), and $50 \mu \mathrm{g} / \mathrm{ml}$ gramicidin D. Gramicidin was dissolved from a freshly thawed aliquot of a dimethylsulfoxide stock solution $(50 \mathrm{mg} / \mathrm{ml})$ just before each experiment. Patch pipettes were fabricated from borosilicate glass (Harvard Apparatus, Edenbridge, UK), and their resistance ranged from 4.5 to $6.5 \mathrm{M} \Omega$. Within $30 \mathrm{~min}$ after gigaseal formation, the access resistance dropped to 50-100 $\mathrm{M} \Omega$, and all experiments with steady increases or sudden drops in this parameter were discarded. The voltage-clamp data were corrected offline for the series-resistance effect. Under the present conditions, the recorded intracellular voltage is affected by a calculated $-3.6 \mathrm{mV}$ liquidjunction potential (Barry, 1994) and by a Nernst potential of approximately $+4 \mathrm{mV}$ across the patch, which is set by the $\mathrm{K}^{+}$concentration that is higher in the pipette than in the neuron (Kim and Trussell, 2007). These errors practically cancel each other, and, hence, no liquid junction potential corrections were applied on the recorded voltages. In the whole-cell patch-clamp recordings, the composition of the patch pipette solution was the following (in mM): $6 \mathrm{KCl}, 111 \mathrm{~K}$-gluconate, $0.5 \mathrm{CaCl}_{2}, 2$ $\mathrm{NaOH}, 10$ glucose, 10 HEPES, $2 \mathrm{Mg}$-ATP, and 5 BAPTA, pH was adjusted to 7.3 with $\mathrm{KOH}$. The resistance of the patch pipettes was 6.5-7.5 $\mathrm{M} \Omega$. The membrane potential values were corrected for a calculated liquid junction potential of $-15.0 \mathrm{mV}$ (Barry, 1994). To minimize the yield of neurons at an immature stage of development, the recordings were made in the outer granule cell layer in the upper blade of the dentate gyrus. The input resistance of the neurons was $412 \pm 19 \mathrm{M} \Omega$ (cf. Liu et al., 1996). We did not find any correlation between input resistance and the $E_{\mathrm{GABA}}$ gradients examined in the present work. It is worth noting that the axon of DGCs has a space constant of $>400 \mu \mathrm{m}$ (Alle and Geiger, 2006), and, with the $50 \mu \mathrm{m}$ distance between the recording site and voltage-clamped soma, a loss of space clamp is not likely to have a significant effect on the present results. Here, one should also note that $E_{\mathrm{GABA}}$ is fairly close to the resting potential, unlike, for example, reversal potentials for currents mediated by ionotropic glutamate receptors. Loss of space clamp is expected to be even smaller in the proximal parts of the dendrites (also recorded at a $50 \mu \mathrm{m}$ distance from the soma) than at the AIS. In the present context, it is notable that, in the whole-cell clamp experiments in which the calculated somatic $E_{\mathrm{GABA}}$ is $-68 \mathrm{mV}$ (corrected for intracellular bicarbonate; $E_{\mathrm{Cl}}$ of $-77 \mathrm{mV}$ ) (Kaila et al., 1993; Kaila, 1994; Farrant and Kaila, 2007), the DGCs were obviously able to cope with part of this minor imposed load $\left(7 \mathrm{mM} \mathrm{Cl}^{-}\right)$even in the somatic compartment, and, hence, the measured somatic $E_{\mathrm{GABA}}$ is more negative $\left(-74.2 \mathrm{mV}\right.$, corresponding to $4.9 \mathrm{~mm}$ intracellular $\left.\mathrm{Cl}^{-}\right)$. A similar deviation of the measured intracellular $\mathrm{Cl}^{-}$from the calculated passive distribution was observed in the neocortical layer $2 / 3$ pyramidal neurons.

Local photolysis of caged GABA. GABA was photolyzed from the $\alpha$-carboxy-2-nitrobenzyl (CNB)-caged GABA compound (Invitrogen, Carlsbad, CA) using local uncaging as described previously (Khirug et al., 2005). Caged GABA ( $2.5 \mathrm{~mm}$ ) was dissolved in the physiological solution and delivered at a flow rate of $1 \mu \mathrm{l} / \mathrm{min}$ to the vicinity of the patchclamped cell using an UltraMicroPump II syringe pump (WPI, Sarasota, FL) and a syringe with an inner tip diameter of $100 \mu \mathrm{m}$. For local photolysis of caged GABA, the 351-364 nm output of a continuous emission argon-ion laser (Coherent Enterprise 653; Coherent, Santa Clara, CA) was delivered to the slice via a multimode optical fiber through an Olympus (Tokyo, Japan) LUMPlanFl $60 \times$ water-immersion objective. The UV beam yielded an uncaging spot of $\sim 10 \mu \mathrm{m}$ in diameter (Khirug et al., 2005) that was focused either at the soma or at the AIS or dendrite at a distance of $50 \mu \mathrm{m}$ from the soma. As shown in the above study, the spatial profile of $\mathrm{GABA}_{\mathrm{A}}$ receptor activation under these conditions precludes any "mixed" responses in which, for instance, the somatic response would be influenced by GABAergic currents generated by the AIS or dendrites. This conclusion was verified in control experiments with flashes of variable positions, durations, and intensities within the range used presently. UV laser power (1-10 $\mathrm{mW}$ at the objective output) and flash duration ( $10-50 \mathrm{~ms})$ were set at a level that provided a good signalto-noise ratio for uncaging-evoked currents. In general, less power and shorter flashes were required to induce somatic responses, perhaps mainly because larger membrane surface areas were covered by the uncaging spot at the soma compared with dendrites and the AIS. At each location, current-voltage relationship was determined by varying the holding potential from -100 to $-40 \mathrm{mV}$ (10 mV steps). Voltage was stepped $200 \mathrm{~ms}$ before each photolysis event and held for $600 \mathrm{~ms}$. Control experiments showed that changing the voltage-step protocol from hyperpolarizing-depolarizing to depolarizing-hyperpolarizing had no effect on the estimated $E_{\mathrm{GABA}}$. Peak current amplitudes were measured and plotted against the holding potential to obtain an estimate of $E_{\mathrm{GABA}}$. For each cell, the somatic, dendritic, and axonal sites were tested in randomized manner. The gradient $\left(\Delta E_{\mathrm{GABA}}\right)$ at the AIS or dendrite was defined as the difference of the local value of $E_{\mathrm{GABA}}$ and the $E_{\mathrm{GABA}}$ at the soma. Control experiments showed that the laser flash evoked no responses in the absence of the CNB-caged GABA. Two types of control experiments were made to ensure that the present technique does not lead to activitydependent ionic shifts (intracellular anion shifts and/or generation of extracellular $\mathrm{K}^{+}$transients) that might have an effect on $E_{\mathrm{GABA}}$ (Kaila et al., 1997; Farrant and Kaila, 2007). First, we found that changing the intensity of the laser pulse within the range used presently had no effect on $E_{\mathrm{GABA}}$. Second, detailed data obtained from the three subcellular compartments examined in five neurons showed that the value of $E_{\mathrm{GABA}}$ was identical when derived from data points taken at different delays from the onset of the uncaging pulse (supplemental Fig. S1, available at www.jneurosci.org as supplemental material). Finally, we have never observed a time-dependent depolarizing shift in $E_{\mathrm{GABA}}$ in response to the uncaging, which would be expected in response to an ion shift. Hence, the $E_{\mathrm{GABA}}$ values recorded in this study are reliable estimates of the steady-state value of this parameter under the present experimental conditions.

Visualization of the neurons. The overall appearance of the neurons in the slices was visualized using Dodt infrared optics (Luigs and Neumann, Ratingen, Germany). Gramicidin patch recordings were made from EGFP-expressing DGCs in slices from the Thy1-mGFP $P^{s} 21$ mice (see above). In addition, gramicidin patch recordings were made from DGCs from $\mathrm{NKCC1}^{-1-}$ mice and their littermates. The DGCs were visualized by single-cell electroporation according to Haas et al. (2001). Briefly, a glass electrode similar to patch pipette $(6-8 \mathrm{~m} \Omega)$ was filled with intracellular solution containing 50-75 $\mu \mathrm{M}$ Alexa Fluor 488 (Invitrogen). The electrode was positioned in the immediate vicinity of a targeted cell, which was then electroporated using single hyperpolarizing square pulses (5-10 ms, 16-18 V) from Axoporator 800A (Molecular Devices, Sunnyvale, CA). In the whole-cell patch-clamp experiments, visualization of the neurons and their axons and dendrites was achieved by adding Alexa Fluor $488(50 \mu \mathrm{M})$ directly to the patch pipette solution. Both EGFP and Alexa Fluor 488 were excited at $488 \mathrm{~nm}$ (Dual Calypso laser; Cobolt, Stockholm, Sweden), and their fluorescence was recorded using a $520 \mathrm{~nm}$ long-pass filter. A confocal microscope (Radiance 2100; Bio-Rad, Hemel 
A

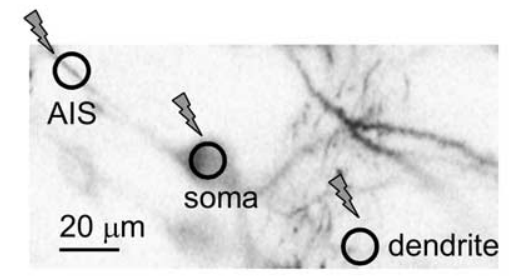

C

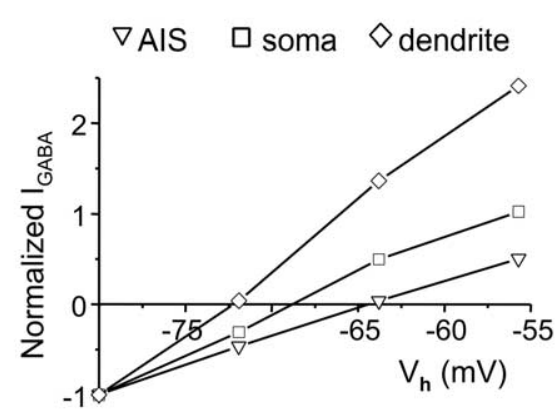

B

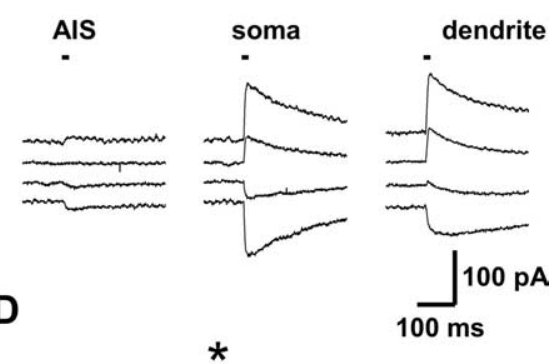

Figure 1. Gramicidin patch-clamp recordings of $G A B A_{A}$ receptor-mediated currents and $E_{G A B A}$ in EGFP-expressing DGCs in mouse hippocampal slices. $A$, Confocal image of a DGC (inverted gray scale) with the three uncaging spots indicated by circles and flash symbols. $\boldsymbol{B}$, Recordings of uncaging-induced $\mathrm{GABA}_{\mathrm{A}}$-mediated currents and $E_{\mathrm{GABA}}$ at the soma, AIS, and dendrite (at a distance of $50 \mu \mathrm{m}$ from the soma). Uncaging flash indicated by horizontal bars in this and subsequent figures. $C, I-V$ curves based on the specimen recordings shown in $B$ and normalized with respect to peak $I_{G A B A}$ at the most negative holding potential $\left(V_{h}\right)$ tested. $\boldsymbol{D}$, The mean values demonstrate a steep $E_{\mathrm{GABA}}$ gradient with a markedly more positive $E_{G A B A}$ at the AIS versus soma, whereas the dendritic responses reverse at a more negative potential. ${ }^{*} p=0.001,{ }^{\#} p=0.014$, based on the Wilcoxon's signed-rank test. The values for $n$ are shown in brackets. Error bars in this and subsequent figures represent SEM.

A
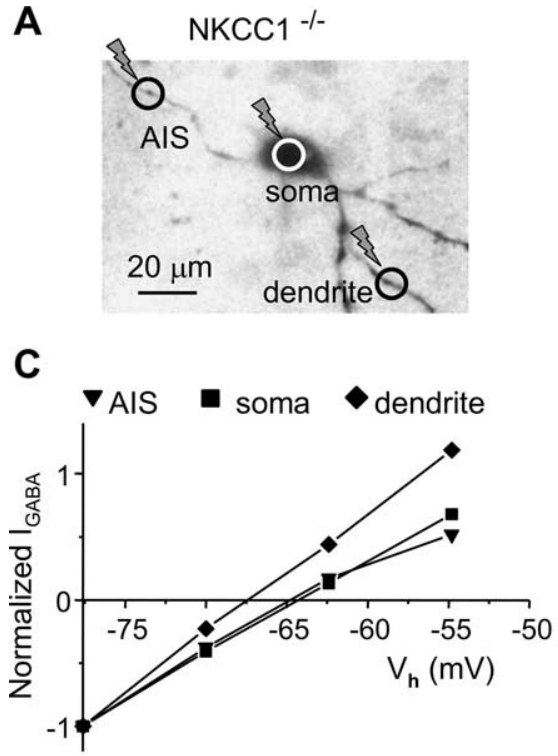

B

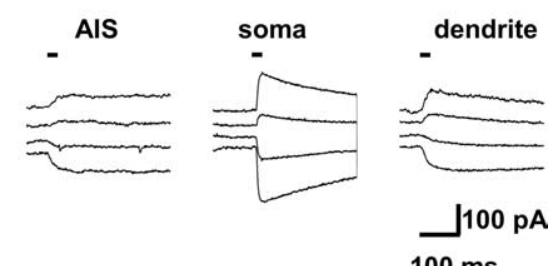

D

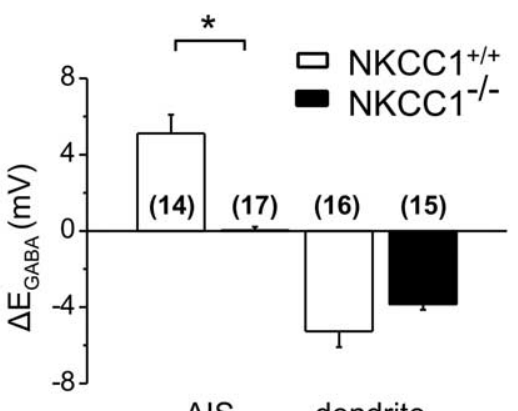

AIS dendrite

Figure 2. Gramicidin patch-clamp recordings of $E_{\mathrm{GABA}}$ gradients in $\mathrm{DGC}$ in slices from $\mathrm{NKCC}^{-1-}$ mice and from their WT littermates. $\boldsymbol{A}$, Confocal image of an $N K C \mathrm{C}^{-1-}$ DGC (inverted grayscale) with the three uncaging spots indicated by flash symbols. $\boldsymbol{B}$, Recordings of $\mathrm{GABA}_{\mathrm{A}}$-mediated currents and $E_{\mathrm{GABA}}$ in an $N \mathrm{NCC}^{-1-}$ neuron. $\boldsymbol{C}, \mathrm{I}-\mathrm{V}$ curves based on the recordings shown in $\boldsymbol{B}$. $\boldsymbol{D}$, The mean values demonstrate that, in the $N K C C 1^{-/-}$neurons, there is no $E_{\mathrm{GABA}}$ gradient $\left(\Delta E_{\mathrm{GABA}}\right)$ between the AIS and the soma. In line with this, there is a significant difference of $5 \mathrm{mV}$ in the AIS $\Delta E_{G A B A}$ between neurons from the $N K C C^{-1-}$ mice and their WT littermates ( ${ }^{*} p \ll 0.001$ ) based on the $t$ test with the values for $n$ shown in brackets. The corresponding dendritic $\Delta E_{\mathrm{GABA}}$ values are not statistically different ( $p=0.2$ ).

Hempstead, UK) was used for real-time imaging and three-dimensional reconstruction of confocal image stacks. In the DGCs, identification of the axons is straightforward because these cells are devoid of basal dendrites in their axonal field. In the layer $2 / 3$ neocortical pyramidal neu- rons, axons were readily distinguished from dendrites by lack of branching and absence of dendritic spines. Care was taken to select pyramidal neurons that had a morphology and orientation that permitted directing the uncaging beam to the AIS in a manner that did not affect any dendritic processes.

Statistical analysis. Averaged data are presented as mean \pm SEM. Statistical significance was assessed using Wilcoxon's signed-rank test or Student's $t$ test as indicated in the figure legends.

\section{Results}

First, we examined whether an $E_{\mathrm{GABA}}$ gradient can be observed under nonperturbed conditions in DGCs that are known to be heavily innervated by AACs (Freund and Buzsaki, 1996; Somogyi et al., 1998). Currents evoked by uncaging of GABA were recorded using the gramicidin perforated patch-clamp technique in hippocampal slices in which EGFP was expressed in a subset of DGCs (De Paola et al., 2003; Galimberti et al., 2006) (see Materials and Methods). Local uncaging of GABA (Khirug et al., 2005) on AISs, somata, and dendrites produced currents with $E_{\mathrm{GABA}}$ values of $-59.4 \pm 1.5 \mathrm{mV}(n=14)$, $-65.8 \pm 1.2 \mathrm{mV}(n=14)$, and $-70.9 \pm$ $1.5 \mathrm{mV}(n=10)$, respectively (Fig. 1$)$. These data indicate a marked depolarizing driving force of $\sim 13 \mathrm{mV}$ for the GABAergic AIS responses from the resting membrane potential of $-72.7 \pm 2.6 \mathrm{mV}(n=$ 14). The dendritic responses reversed at a more negative level (by $\sim 5 \mathrm{mV}$ ) than the somatic ones, which shows that, in addition to the axo-somatic $E_{\mathrm{GABA}}$ gradient $\left(\Delta E_{\mathrm{GABA}}\right.$ of $\sim 6.5 \mathrm{mV}$ ), a somato-dendritic $\Delta E_{\mathrm{GABA}}$ is also maintained by the DGCs. Assuming an intracellular $\mathrm{pH}$ of $\sim 7.2$, the intracellular levels of $\mathrm{Cl}^{-}\left(\left[\mathrm{Cl}_{\mathrm{i}}\right]\right)$ calculated on the basis of the above $E_{\mathrm{GABA}}$ values (Kaila et al., 1993; Farrant and Kaila, 2007) are 11, 7.9, and $6.0 \mathrm{~mm}$ for the AIS, soma, and dendrite, respectively. A set of control experiments showed that the currents induced by GABA uncaging were fully blocked by $10 \mu \mathrm{M}$ bicuculline (data not shown).

To examine whether the $\mathrm{Na}-\mathrm{K}-2 \mathrm{Cl}$ transporter NKCC1 (Payne et al., 2003) is responsible for the depolarizing GABAergic response in the AIS, we made gramicidin perforated patch recordings from DGCs of $\mathrm{NKCC1}^{-/-}$mice (Pace et al., 2000) and their WT littermates. Cells were visualized using electroporation for staining with Alexa Fluor 488 (Fig. 2). The WT neurons showed an axo-somatic $\Delta E_{\mathrm{GABA}}$ that was similar $(\sim 5 \mathrm{mV})$ to the one described above in the Thy1-mGFP neurons with AIS, somatic, and dendritic $E_{\mathrm{GABA}}$ values of $-61.3 \pm 2.4 \mathrm{mV}(n=14),-66.0 \pm 1.6 \mathrm{mV}(n=22)$, 
and $-71.0 \pm 2.0 \mathrm{mV}(n=16)$, respectively. Notably, in identical recordings from the $\mathrm{NKCC1}^{-/-}$neurons, there was no axo-somatic $E_{\mathrm{GABA}}$ gradient; the values for $E_{\mathrm{GABA}}$ at the AIS and soma were similar, $-70.5 \pm 1.5 \mathrm{mV}(n=17)$ and $-70.3 \pm 1.5$ $\mathrm{mV}(n=18)$, respectively. However, a somato-dendritic $\Delta E_{\mathrm{GABA}}$ similar to that in the WT neurons was still observed (dendritic $E_{\mathrm{GABA}}$ of $\left.-74.6 \pm 1.7 \mathrm{mV} ; n=15\right)$. These data indicate a key role for NKCC1 in the generation and maintenance of the chloride gradient that results in depolarizing GABA responses in the AIS of mouse DGCs and suggest that NKCC1 has no significant influence on dendritic $E_{\mathrm{GABA}}$. Interestingly, the above observations are not compatible with the idea that the somatodendritic $E_{\mathrm{GABA}}$ gradient is set by NKCC1 and KCC2. The putative transport mechanism underlying this gradient is not in the focus of the present work, but preliminary observations point to a role of a bicarbonate-dependent somatic transporter that accumulates chloride in the DGCs (our unpublished data).

To examine possible species- and cellspecific differences in the generation of depolarizing AIS GABA responses, we performed whole-cell recordings of the above type in rat DGCs as well as in rat neocortical layer 2/3 pyramidal neurons. Previous work has shown that plasmalemmal ion transporters are able to maintain $\mathrm{Cl}^{-}$gradients and consequent $E_{\mathrm{GABA}}$ gradients along the dendrites during a somatic $\mathrm{Cl}^{-}$ load under whole-cell clamp conditions (Jarolimek et al., 1999; Khirug et al., 2005). A robust axo-somatic $E_{\mathrm{GABA}}$ gradient $(\sim 7$ $\mathrm{mV}$ ) was seen in rat DGCs, with AIS, somatic, and dendritic $E_{\mathrm{GABA}}$ values of $-67.2 \pm 1.7 \mathrm{mV}(n=14),-74.2 \pm 1.2$ $\mathrm{mV}(n=14)$, and $-78.8 \pm 1.1 \mathrm{mV}(n=$ 14), respectively (Fig. $3 A-C$ ). Chloride uptake mediated by NKCC1 can be selectively blocked using low concentrations of bumetanide (Payne et al., 2003). A series of experiments showed that the axo-somatic $\Delta E_{\mathrm{GABA}}$ in slices exposed to $10 \mu \mathrm{M}$ bumetanide was collapsed, with $E_{\mathrm{GABA}}$ in the AIS at $-75.8 \pm 1.4 \mathrm{mV}(n=7)$ and $-73.7 \pm$ $1.8 \mathrm{mV}(n=6)$ in the soma (Fig. $3 D)$.

However, in agreement with the data on the $\mathrm{NKCC1}^{-1-}$ DGCs, the somato-dendritic $\Delta E_{\mathrm{GABA}}(\sim 5 \mathrm{mV})$ was not affected by bumetanide (dendritic $E_{\mathrm{GABA}}$ of $-78.6 \pm 2.6 \mathrm{mV} ; n=6$ ).

The whole-cell recordings in rat neocortical layer $2 / 3$ pyramidal neurons (Fig. 4) also revealed an $E_{\mathrm{GABA}}$ gradient between the AIS and soma of $\sim 7 \mathrm{mV}$, with AIS, somatic, and dendritic $E_{\mathrm{GABA}}$ levels of $-69.2 \pm 1.7 \mathrm{mV}(n=4),-76.1 \pm 0.9 \mathrm{mV}(n=9)$, and $-80.7 \pm 1.0 \mathrm{mV}(n=6)$, respectively. In two of two slices tested (data not shown), the axo-somatic gradient was abolished by bumetanide $\left(\Delta E_{\mathrm{GABA}}\right.$ of $\left.<1 \mathrm{mV}\right)$, with no observable effect on the somato-dendritic $\Delta E_{\mathrm{GABA}}$.
A
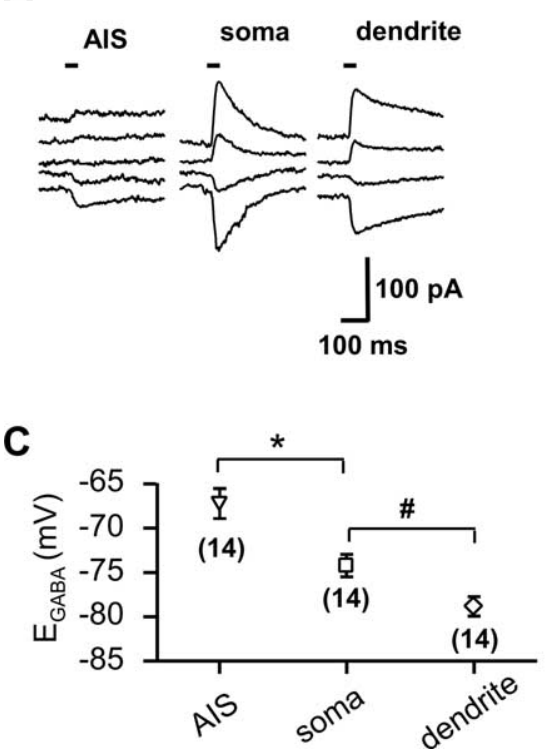

B

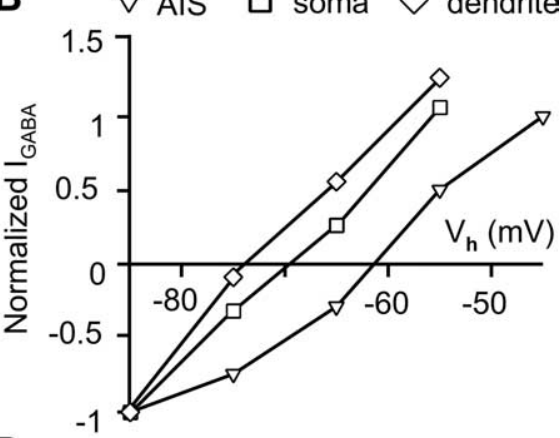

D

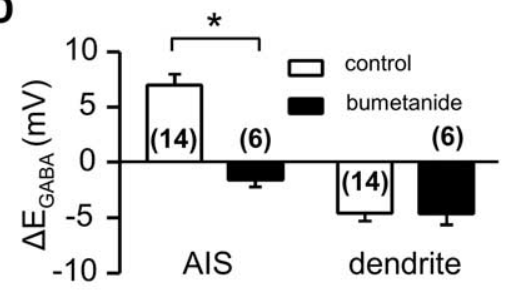

Figure 3. Whole-cell patch-clamp recordings of $G A B A_{A}$-mediated currents and $E_{G A B A}$ gradients in rat $D G C s$. $A$, Sample recordings. $\boldsymbol{B}$, Normalized $I-V$ curves based on the recordings shown in $A$. $C$, The mean values reveal a robust axo-somato-dendritic $E_{\mathrm{GABA}}$ gradient. ${ }^{*} p=0.001,{ }^{\sharp} p=0.001$, based on the Wilcoxon's signed-rank test. $\boldsymbol{D}$, In the presence of $10 \mu \mathrm{m}$ bumetanide, $E_{\mathrm{GABA}}$ at the AIS shifts to the level at the soma, whereas the somato-dendritic $\Delta E_{\mathrm{GABA}}$ is not affected. ${ }^{*} p=0.005$, based on the $t$ test. The values for $n$ are shown in brackets.

A

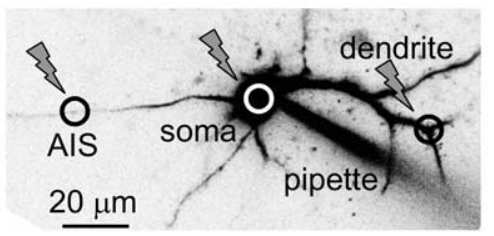

C

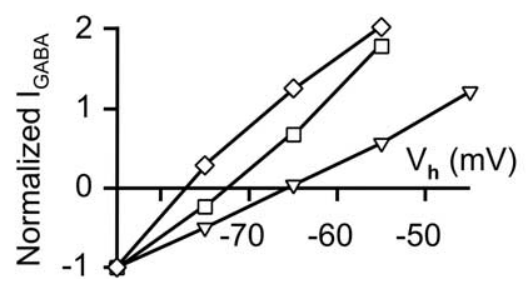

B
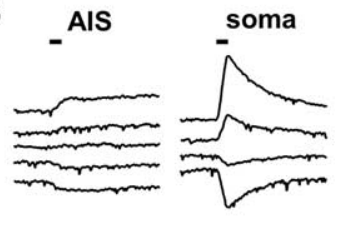

dendrite

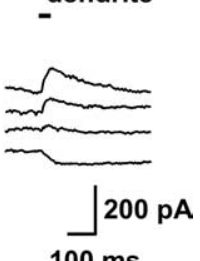

D

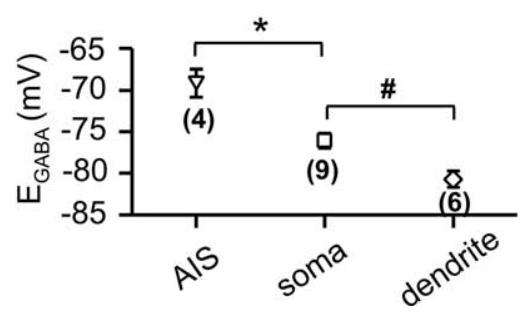

Figure 4. Whole-cell patch-clamp measurements of $\mathrm{GABA}_{A}$ receptor-mediated currents and $E_{\mathrm{GABA}}$ in layer $2 / 3$ neocortical neurons. $A$, Confocal image of pyramidal cell (inverted grayscale) with the three uncaging spots indicated by flash symbols; patch pipette containing Alexa Fluor 488 shown at the bottom right of the image. $\boldsymbol{B}$, Sample recordings. $\boldsymbol{C}$, Normalized $I-V$ curves based on the recordings shown in $\boldsymbol{B}$. $\boldsymbol{D}$, The mean values demonstrate an axo-somato-dendritic $E_{\mathrm{GABA}}$ gradient. ${ }^{*} p=0.02,{ }^{*} p=0.03$, based on the Wilcoxon's signed-rank test. The values for $n$ are shown in brackets.

\section{Discussion}

There is much evidence that the strongly depolarizing action of GABA in immature cortical pyramidal neurons is attributable to $\mathrm{Cl}^{-}$uptake by NKCC1 (Yamada et al., 2004; Sipilä et al., 2006; Achilles et al., 2007; Brumback and Staley, 2008). During the first 2 postnatal weeks, the developmental downregulation of $\mathrm{Cl}^{-}$uptake by NKCC1 and the upregulation of $\mathrm{Cl}^{-}$extrusion by KCC2 produce a negative shift in $E_{\mathrm{GABA}}$ that leads to hyperpolarizing $\mathrm{GABA}_{\mathrm{A}}$ responses (Rivera et al., 1999; Payne et al., 2003; Yamada et al., 2004). However, recent work has demonstrated depolarizing actions of GABA in presynaptic terminals, which are based on 
a higher $\left[\mathrm{Cl}^{-}\right]_{\mathrm{i}}$ in the presynaptic axonal compartment than in somata (Price and Trussell, 2006; Stell et al., 2007). Furthermore, selective activation of AACs has been shown to evoke a depolarizing $\mathrm{GABA}_{\mathrm{A}}$ response at the AIS of mature neocortical pyramids (Szabadics et al., 2006).

Our work demonstrates that the depolarizing action of AACs at the AIS of cortical pyramidal neurons is attributable to $\mathrm{Cl}^{-}$uptake mediated by NKCC1. In view of the high expression levels of KCC2 in the somata and dendrites and absence in the AIS (Szabadics et al., 2006) (see also Gulyás et al., 2001), the axo-somatic $\mathrm{Cl}^{-}$gradient is readily explained on the basis of the distinct subcellular expression patterns of these two transporters. Interestingly, our work also points to the presence of a somatic $\mathrm{Cl}^{-}$uptake mechanism that generates the somato-dendritic gradient. Preliminary experiments suggest a bicarbonate-dependent mechanism of chloride uptake (our unpublished data), which will be a subject of future studies. Notably, however, the present results indicate that this putative transporter does not play a role in the NKCC1-dependent depolarizing responses generated by the AIS.

In view of the similarity of our observations in hippocampal DGCs (both mouse and rat) and neocortical layer $2 / 3$ pyramidal neurons, it appears that the presence of a prominent steady-state axo-somato-dendritic $E_{\mathrm{GABA}}$ gradient is a common property of most if not all types of cortical principal neurons (for data on cortical interneurons, see Martina et al., 2001; Banke and McBain, 2006). This is an important conclusion with several implications. First of all, it is obvious that the widely used manner of assigning a "typical" $E_{\mathrm{GABA}}$ value to a given principal neuron is not correct. In view of the high subcellular target specificity of interneurons onto principal neurons (Freund and Buzsaki, 1996), a more appropriate approach is to specify the $E_{\mathrm{GABA}}$ level of a given interneuronal input in the postsynaptic neuron. This also points to a need to reexamine the "developmental switch" (or rather "shift") (Farrant and Kaila, 2007) from depolarizing to hyperpolarizing GABA transmission (Rivera et al., 1999; Payne et al., 2003) at the subcellular level. Such information is necessary for understanding the various modes of functionally inhibitory and excitatory actions of GABAergic transmission in the generation of early endogenous activity (Ben-Ari, 2002; Sipilä and Kaila, 2007), as well as of sharp-wave ripple complexes (Klausberger et al., 2003) and ongoing oscillations (Bartos et al., 2007; Mann and Paulsen, 2007) in the mature brain.

\section{References}

Achilles K, Okabe A, Ikeda M, Shimizu-Okabe C, Yamada J, Fukuda A, Luhmann HJ, Kilb W (2007) Kinetic properties of $\mathrm{Cl}$ uptake mediated by $\mathrm{Na}^{+}$-dependent $\mathrm{K}^{+}-2 \mathrm{Cl}$ cotransport in immature rat neocortical neurons. J Neurosci 27:8616-8627.

Alle H, Geiger JR (2006) Combined analog and action potential coding in hippocampal mossy fibers. Science 311:1290-1293.

Banke TG, McBain CJ (2006) GABAergic input onto CA3 hippocampal interneurons remains shunting throughout development. J Neurosci 26:11720-11725.

Barry PH (1994) JPCalc, a software package for calculating liquid junction potential corrections in patch-clamp, intracellular, epithelial and bilayer measurements and for correcting junction potential measurements. J Neurosci Methods 51:107-116.

Bartos M, Vida I, Jonas P (2007) Synaptic mechanisms of synchronized gamma oscillations in inhibitory interneuron networks. Nat Rev Neurosci 8:45-56.

Ben-Ari Y (2002) Excitatory actions of GABA during development: the nature of the nurture. Nat Rev Neurosci 3:728-739.

Brumback AC, Staley KJ (2008) Thermodynamic regulation of NKCC1mediated $\mathrm{Cl}^{-}$cotransport underlies plasticity of $\mathrm{GABA}_{\mathrm{A}}$ signaling in neonatal neurons. J Neurosci 28:1301-1312.

De Paola V, Arber S, Caroni P (2003) AMPA receptors regulate dynamic equilibrium of presynaptic terminals in mature hippocampal networks. Nat Neurosci 6:491-500.

Farrant M, Kaila K (2007) The cellular, molecular and ionic basis of GABA receptor signalling. Prog Brain Res 160:59-87.

Freund TF, Buzsaki G (1996) Interneurons of the hippocampus. Hippocampus $6: 347-470$.

Galimberti I, Gogolla N, Alberi S, Santos AF, Muller D, Caroni P (2006) Long-term rearrangements of hippocampal mossy fiber terminal connectivity in the adult regulated by experience. Neuron 50:749-763.

Gulyás AI, Sík A, Payne JA, Kaila K, Freund TF (2001) The K-Cl cotransporter, KCC2, is highly expressed in the vicinity of excitatory synapses in the rat hippocampus. Eur J Neurosci 13:2205-2217.

Haas K, Sin WC, Javaherian A, Li Z, Cline HT (2001) Single-cell electroporation for gene transfer in vivo. Neuron 29:583-591.

Jarolimek W, Lewen A, Misgeld U (1999) A furosemide-sensitive $\mathrm{K}^{+}{ }_{-} \mathrm{Cl}^{-}$ cotransporter counteracts intracellular $\mathrm{Cl}^{-}$accumulation and depletion in cultured rat midbrain neurons. J Neurosci 19:4695-4704.

Kaila K (1994) Ionic basis of GABAA receptor channel function in the nervous system. Prog Neurobiol 42:489-537.

Kaila K, Voipio J, Paalasmaa P, Pasternack M, Deisz R (1993) The role of bicarbonate in $\mathrm{GABA}_{\mathrm{A}}$ receptor-mediated IPSPs of rat neocortical neurones. J Physiol (Lond) 464:273-289.

Kaila K, Lamsa K, Smirnov S, Taira T, Voipio J (1997) Long-lasting GABAmediated depolarization evoked by high-frequency stimulation in pyramidal neurons of rat hippocampal slice is attributable to a networkdriven, bicarbonate-dependent $\mathrm{K}^{+}$transient. J Neurosci 17:7662-7672.

Khirug S, Huttu K, Ludwig A, Smirnov S, Voipio J, Rivera C, Kaila K, Khiroug L (2005) Distinct properties of functional KCC2 expression in immature mouse hippocampal neurons in culture and in acute slices. Eur J Neurosci 21:899-904

Kim Y, Trussell LO (2007) Ion channels generating complex spikes in cartwheel cells of the dorsal cochlear nucleus. J Neurophysiol 97:1705-1725.

Klausberger T, Magill PJ, Marton LF, Roberts JD, Cobden PM, Buzsaki G, Somogyi P (2003) Brain-state- and cell-type-specific firing of hippocampal interneurons in vivo. Nature 421:844-848.

Liu YB, Lio PA, Pasternak JF, Trommer BL (1996) Developmental changes in membrane properties and postsynaptic currents of granule cells in rat dentate gyrus. J Neurophysiol 76:1074-1088.

Mann EO, Paulsen O (2007) Role of GABAergic inhibition in hippocampal network oscillations. Trends Neurosci 30:343-349.

Martina M, Royer S, Pare D (2001) Cell-type-specific GABA responses and chloride homeostasis in the cortex and amygdala. J Neurophysiol 86:2887-2895.

Pace AJ, Lee E, Athirakul K, Coffman TM, O’Brien DA, Koller BH (2000) Failure of spermatogenesis in mouse lines deficient in the $\mathrm{Na}^{+}-\mathrm{K}^{+}-2 \mathrm{Cl}^{-}$ cotransporter. J Clin Invest 105:441-450.

Payne JA, Rivera C, Voipio J, Kaila K (2003) Cation-chloride cotransporters in neuronal communication, development and trauma. Trends Neurosci 26:199-206.

Price GD, Trussell LO (2006) Estimate of the chloride concentration in a central glutamatergic terminal: a gramicidin perforated-patch study on the calyx of Held. J Neurosci 26:11432-11436.

Rivera C, Voipio J, Payne JA, Ruusuvuori E, Lahtinen H, Lamsa K, Pirvola U, Saarma M, Kaila K (1999) The $\mathrm{K}^{+} / \mathrm{Cl}^{-}$co-transporter KCC2 renders GABA hyperpolarizing during neuronal maturation. Nature 397:251-255.

Sipilä ST, Kaila K (2007) GABAergic control of CA3-driven network events in the developing hippocampus. Results Probl Cell Differ 44:99-121.

Sipilä ST, Schuchmann S, Voipio J, Yamada J, Kaila K (2006) The cationchloride cotransporter NKCC1 promotes sharp waves in the neonatal rat hippocampus. J Physiol (Lond) 573:765-773.

Somogyi P, Tamas G, Lujan R, Buhl EH (1998) Salient features of synaptic organisation in the cerebral cortex. Brain Res Brain Res Rev 26:113-135.

Stell BM, Rostaing P, Triller A, Marty A (2007) Activation of presynaptic $\mathrm{GABA}_{\mathrm{A}}$ receptors induces glutamate release from parallel fiber synapses. J Neurosci 27:9022-9031.

Szabadics J, Varga C, Molnar G, Olah S, Barzo P, Tamas G (2006) Excitatory effect of GABAergic axo-axonic cells in cortical microcircuits. Science 311:233-235.

Yamada J, Okabe A, Toyoda H, Kilb W, Luhmann HJ, Fukuda A (2004) $\mathrm{Cl}^{-}$ uptake promoting depolarizing GABA actions in immature rat neocortical neurones is mediated by NKCC1. J Physiol (Lond) 557:829-841. 